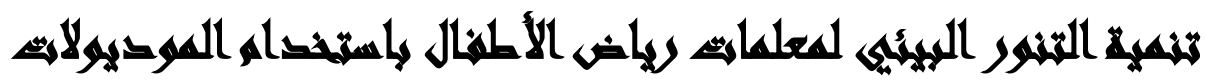

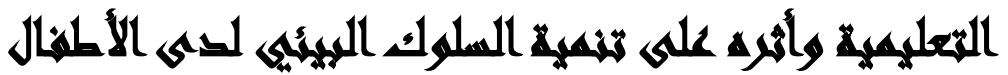

\section{[1 17$]$}

\author{
ليلي أحمد كرم الدين(')- عاطف عدلي فهمي(Y) - ميلاد وليم عبدالله
}

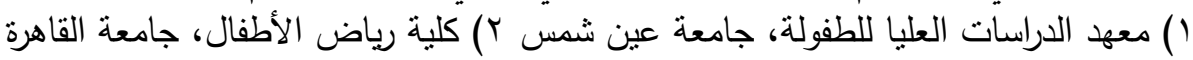

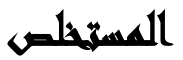

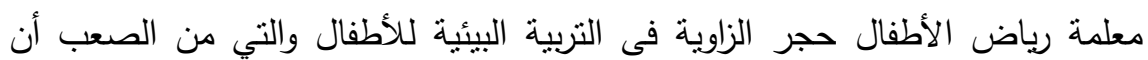

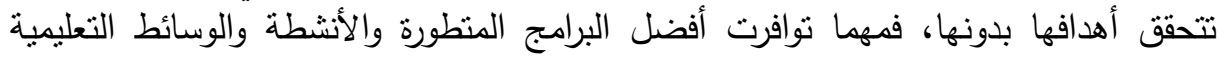

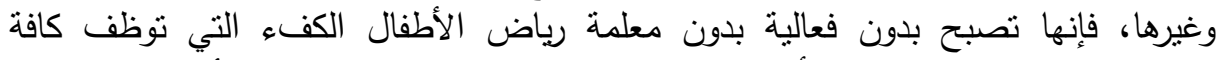

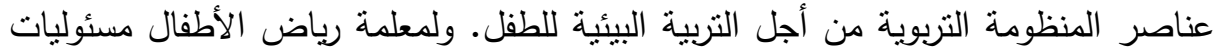

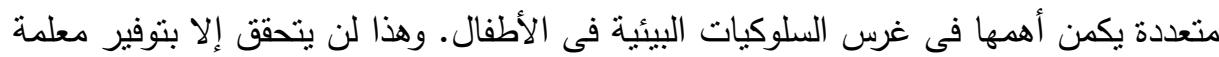

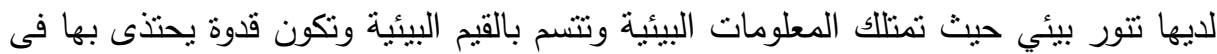

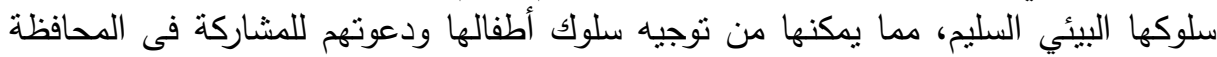
على البيئة وحمايتها وحل مشكلاتها.

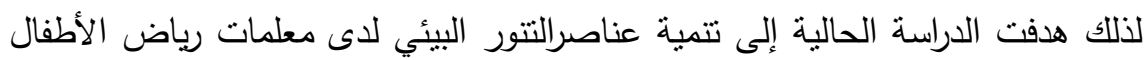
وقياس أثز ذلك على سلوك أطفالهن. وأعتمدت الدراسة في جمع البيانات على تطبيق الئن الأدوات

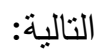
ا ا إعداد أربعة موديولات تعليمية لتتمية عناصر التتور البيئي.

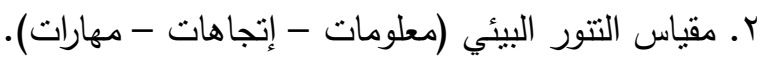

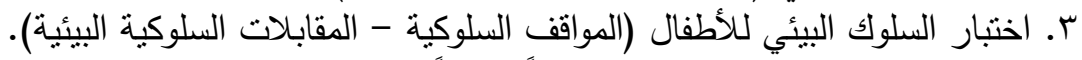

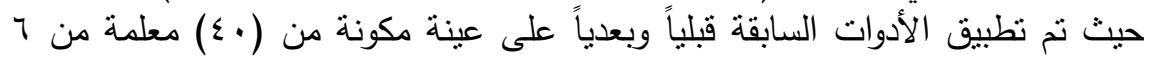

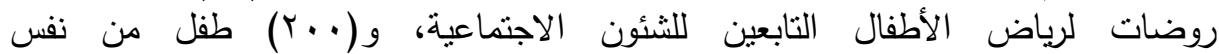

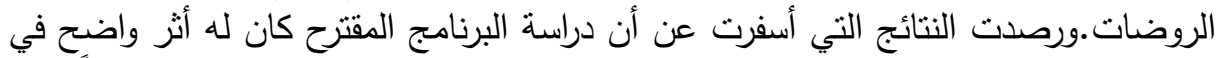

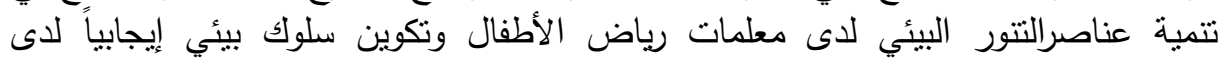

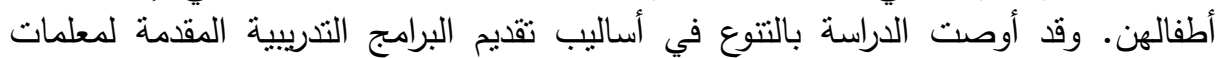

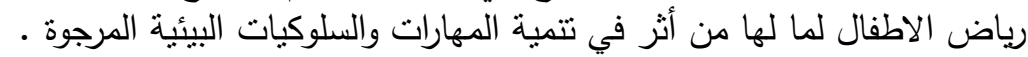
الكلمات المفتاحية: الموديولات التعليمية - التتور البيئي - معلمات رياض الئية التئية الأطفال - أطفال

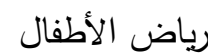

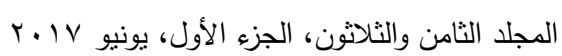




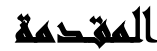

لقد خلق الله الانسان وكرمه عن سائر المخلوقات وخلقه تاجاً للخليقة وخلق له بيئة متوازنة ومتكاملة وأمره أن يعمر فيها ولا يفسدها حتى يضمن سلامته، وسلامة الآخرين لكن سلوك الانسان السلبي أتجاه البيئة بدعوة التتمية الكبري، والنقلة الحضارية التي حدثت للبيئة لكنها في الوقت نفسه تجاهلت هذه النقلة البيئة نفسها وافقدتتها نوازنها وأدت إلى أختلال توازن البيئة وذلك نتيجة عدم تتوره بالمعلومات البيئة والمشكلات البيئة وعدم تكون اتجاهات بيئية لديه فأدي كل ذلك إلى عدم القدرة على اتخاذ القرارات البيئية الايجابية.لذلك فالأجيال الحالية

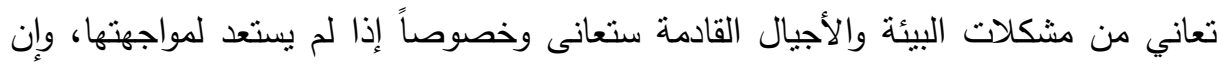
بدأنا فى هذا الاستعداد فمن الواجب أن يبدأ من مرحلة الطفولة المبكرة. وهنا تبرز أهمية الدور

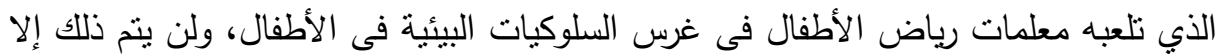

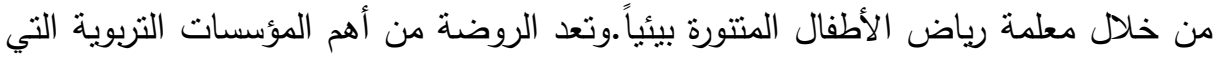
يوكل إليها تحقيق أهداف التربية البيئية للأطفال. وتجدر الإثارة إلى أن التربية البيئية ليست

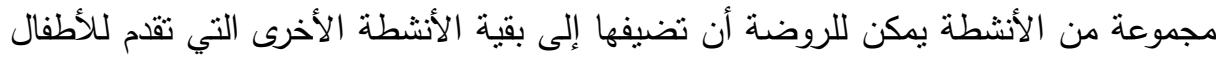

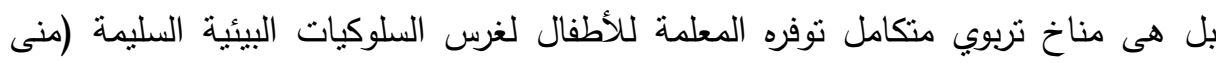

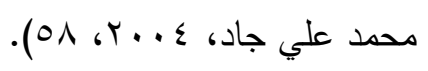
ومعلمة رياض الأطفال هي الأساس فى التربية البيئية للأطفال فهي حجر الزاوية والتى

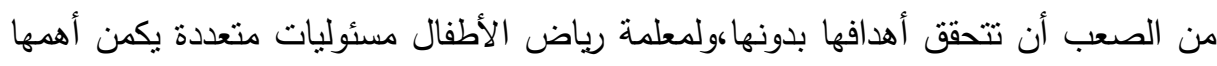
فى غرس السلوكيات البيئية فى الأطفال. وهذا لن يتحقق إلا بتوفير معلمة لديها نتور بيئي

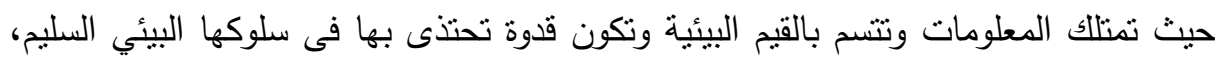
مما يمكنها من نوجية سلوك أطفالها ودعوتهم للمشاركة فى المحافظة على البيئة وحمايتها

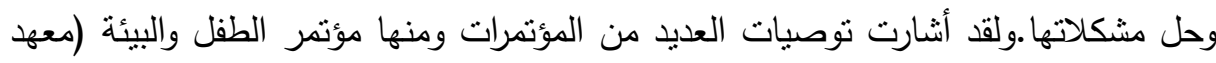

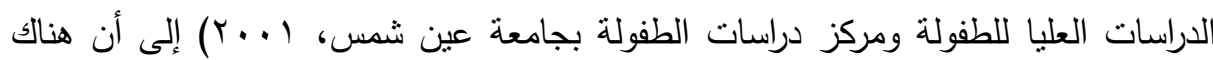
حاجة إلى تتور معلمة رياض الأطفال بيئياً، وضرورة إعداد برامج تدريبية نهتم بتتمية التتور

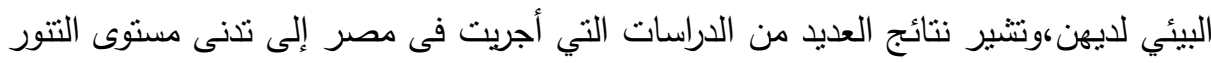


البيئي لدى المعلمين بل غياب كثثر من المعلومات البيئية لديهم، وافتقارهم للمهارات

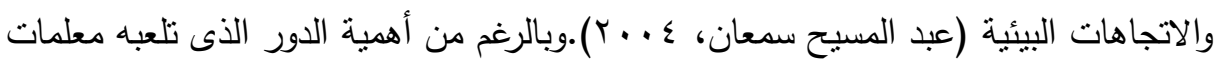
رياض الأطفال فى تشكيل السلوكيات البيئية لطفل الروضة، إلا أن برامج إعدادها وتدريبها

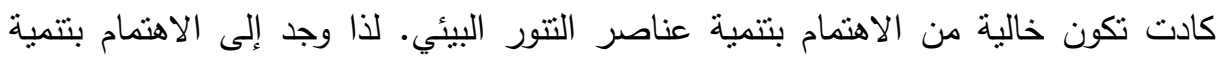

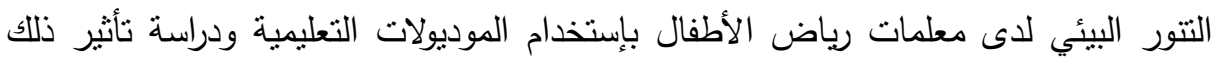

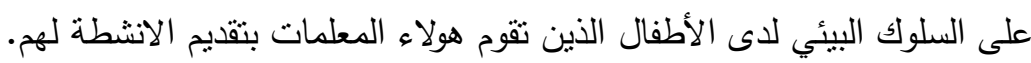

\section{And}

تشير نتائج العديد من الدراسات التي أجريت فى مصر إلى تدنى مستوى التتور البيئي لدى المعلمين بل غياب كثير من المعلومات البيئية لديهم، وافتقارهم للمهارات والاتجاهات

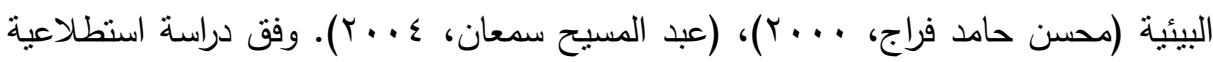

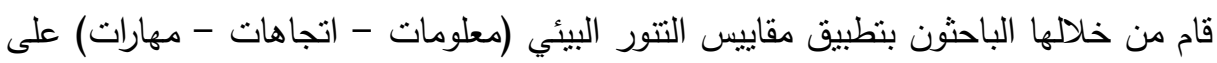

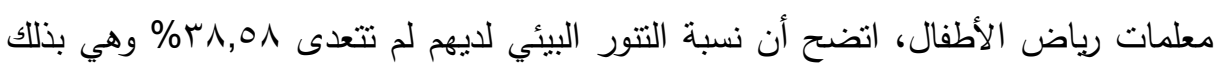

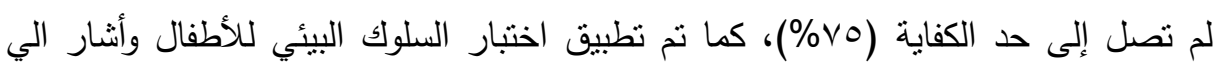

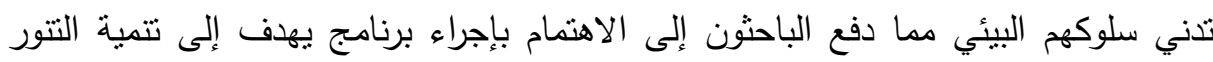

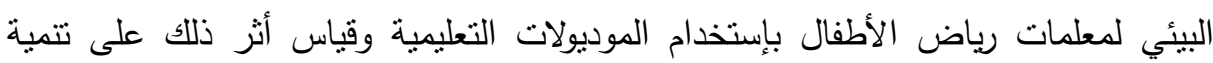
السلوك البيئي لدى أطفال الروضات.

\section{أسهلم المهيث}

سيحاول البحث الإجابة عن السؤال الرئيس الآتي:ما فعالية أستخدام موديولات تعليمية مقترحة لتتمية عناصر التتور البيئي للمعلمات وأثرها في تتمية السلوك البيئي لدى لإئي أطفالهن بوينبيثق من هذا النساؤل الرئيسي الأسئلة الفرعية التالية:

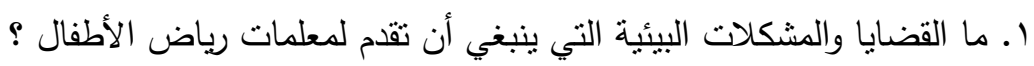

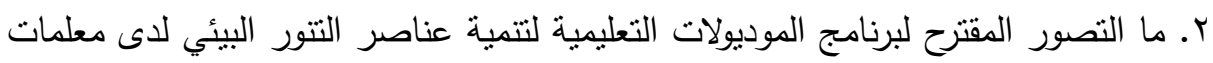
رياض الأطفال؟ مأ 
r. ما فعالية التصور المقترح في تتمية عناصر التتور البيئي لاى معلمات رياض الأطفال باستخدام الموديولات التعليمية؟

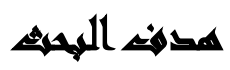

ا. تتمية عناصر التتور البيئي (معلومات - اتجاهات - مهارات) لاى معلمات رياض الأطفال بإستخدام الموديولات التعليمية r. التعرف علي أثر ذلك في تتمية السلوك البيئي لدى أطفالهن.

\section{Aast}

ا. الحدود البشرية: عينة مكونة من (•؟) معلمة من معلمات رياض الأطفال وعدد

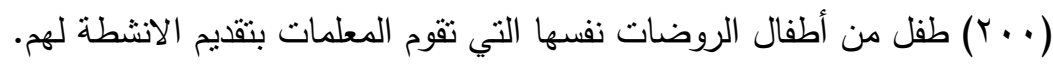

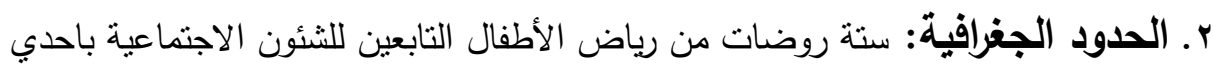

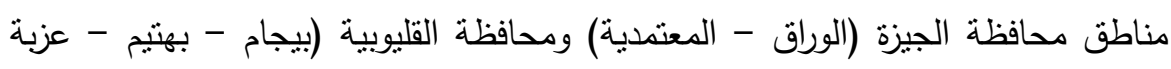

$$
\text { رستم شبرا الخيمة). }
$$

r. الحدود الزمنية: تم تطبيق الادوات خلال ثلاثة شهور (من شهر يونيه حتي سبتمبر

لعام 7 ـ ـ r م) باستخدام العديد من الأساليب المناسبة لتحقيق اهداف الدراسة الحالية.

\section{أسوايت القراسلة}

يعد ويستخدم الباحث الأدوات الاتية لتحقيق أهداف البحث: 1. إعداد قائمة بالقضايا والمشكلات البيئية اللازمة لتتمية عناصر التنور البيئي لدى معلمات البات الباتيف

$$
\text { رياض الأطفال. }
$$

r. إعداد أربعة موديولات تعليمية متضمنة أبعادا بيئية لتتمية عناصر التتور البيئي.

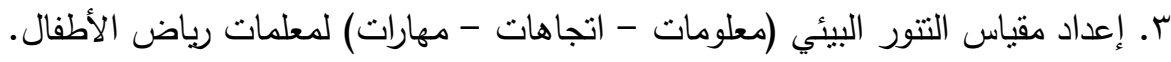
ع. تصميم مقياس السلوك البيئي (المواقف السلوكية - المقابلات السلوكية البيئية) لأطفال تلكي

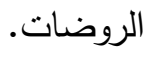




\section{هنهمج الصوراسمة}

تم استخدم المنهج الوصفي لتحليل البرامج المقدمة للمعلمات وتفسيرها، وجمع الحقائق والبيانات عنها.ثم استخدم المنهج التجريبي، لتجريب البرنامج المقترح.

\section{هبروض الهمبث}

سعى البحث الحالي إلى التحقق من صحة الفروض التالية: ا. توجد فروق ذات دلالة إحصائية بين متوسط درجات المعلمات في مقياس التنور البيئي ككل قبل وبعد دراسة البرنامج المقترح لصالح النطبيق البعدي. r. توجد فروق ذات دلالة إحصائية بين منوسط درجات المعلمات في أختبار المعلومات البيئية قبل وبعد دراسة البرنامج المقترح لصالح التطبيق البعدي. r. توجد فروق ذات دلالة إحصائية بين متوسط درجات المعلمات في مقياس الاتجاهات البيئة قبل وبعد دراسة البرنامج المقترح لصالح التطبيق البعدي. ع. توجد فروق ذات دلالة إحصائية بين منوسط درجات المعلمات في مقياس المهارات البيئية قبل وبعد دراسة البرنامج المقترح لصالح التطبيق البعدي.

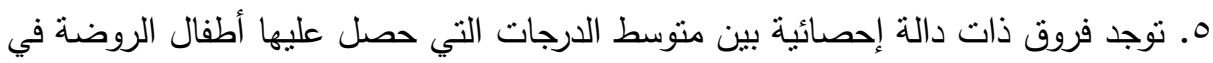
أختبار السلوكيات البيئية (المواقف السلوكية - المقابلات السلوكية البيئية) قبل وبعد دراسة البرنامج من قبل المعلمات لصالح التطبيق البعدي.

\section{مصطالحاهث الهيه}

التتور البيئي: أكتساب المعلم لقدر من المعارف عن البيئة ومفاهيمها ونظمها ومشكلاتها، تودي به إلي تكوين وعي وإتجاهات إيجابية ليتعامل مع البيئة ويتخذ قرارات مناسبة بشأنها،

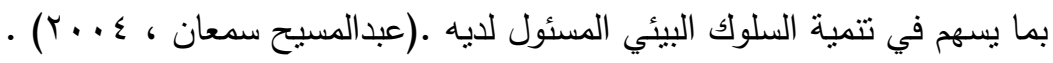
الموديولات التعليمية: وحدات دراسية تعالج جزء من موضوع أو من وحدة دراسية كبيرة ينت

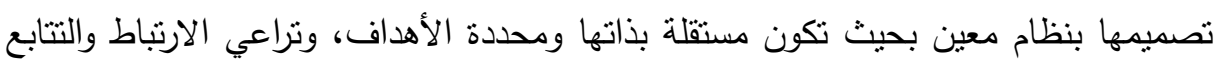

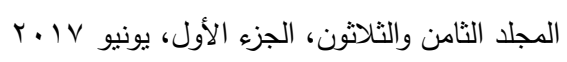


في بناء الدرس وتتظيمه وتوفر مصادر التعلم المختلفة التي تساعد علي فهم محتواه وتحدد المطلوب من كل متعلم في كل خطوة من خطواتها وبعد كل خطوة تقدم التعزيز المطلوب مباشرة ، وفي النهاية يتم التعليق من خلال المشاركة الفعالة من المتعلم وفق قدراته وسرعته

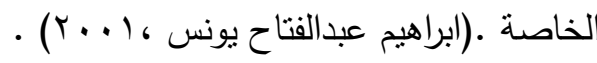
التتور البيئي: يعيش الانسان دوما في مجتمع فيصنع ويبتكر كل شئ حوله ليتكيف مع عناصر الحياة دائمة التغير ومع التطور المستمر للإنسان تزايدت حاجاته وتحدياته وسيطرت علي تفكيره بعض المشكلات ، وبعد أن أصبح العالم قرية صغيرة منفتحة علي العالم أصبح التتور ضرورة ملحة للمواطن والمعلم والمتعلم للصغير والكبير . فالتتور يتميز بالتتابع والثمول والتكامل وهو شامل لكافة نواحي المعرفة ويساعد الفرد علي إحداث نواصل بين المعرفة المكتسبة وإتجاهات وقيم الفرد المتكونة (الجمعية المصرية للمناهج وطرق التدريس: القاهرة ، . .99 (19 ).

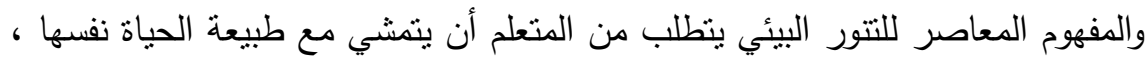
وأن يكون لديه قدرا مناسبا من المعرفة والمهارات المتتوعة والمتعددة ومعرفة عميقة بالاتجاهات والقيم وأن ينعكس كل ذلك علي تصرفاته كمواطن ( فتحية معتوق بن بكري: الجمعية المصرية

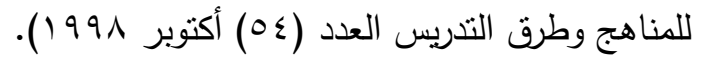
وهذا يعني أننا في حاجة إلي المواطن المتتور في كل مكان وعمل ومهنة فقد يكون التتور علي المستوي المحلي مطلوبا في مرحلة ما ولكن لا يمكن اعتباره المستوي النهائي الذي يمكننا قبوله لأنه هو المرحلة البدائية التي يجب علين ملينا الانطلاق منها لمراحل منتالية ويجب علينا أن نتعداها للوصول لمستوي أخر هو التتور الاقليمي ومنه الي مستويات التتور

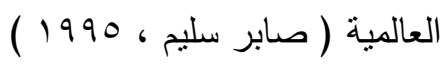

وتعددت أراء الباحثثن حول مفهوم التتور البيئي علي المستوي العربي والعالمي ، حيث

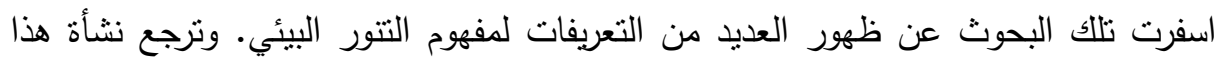
المفهوم (التتور البيئي ) الي الولايات المتحدة الامريكية حيث قدم (روث نتارلز عام 971 ام) 
مقالة مكتوبة عن مفهوم التتور البيئي وذللك كرد فعل إتجاه العبارات المستخدمة في العديد من وسائل الإعلام المختلفة التي تعتبر الأفراد الملوثين للبيئة بإنهم افراد أميين بيئيا.

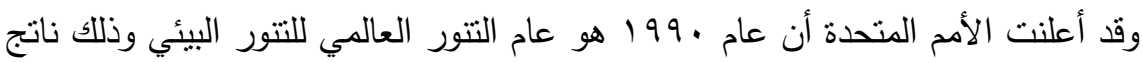
عن تلك المؤتمرات ، وأعتبرت التتور البيئي تتور للمجتمع ككل ويقصد به التربية الفعالة لكل

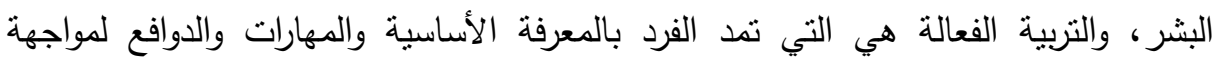
إحتياجات البيئة والمساهمة في التتمية المستدامة. ويثير هاي إين شاي: أن التنور التتور البيئي مفهوم يؤكد علي أن المعلومات مرتبطة بالإتجاهات والسلوكيات التي يسلكها الأفراد بداية من الاجداد حتي الابناء وأنها متوارثة وينت

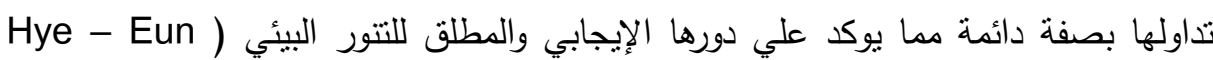
(chu , 2007

عناصر التنور البيئي: لقد احتل مفهوم التتور البيئي اهتمام العديد من المؤتمرات وأثيرت

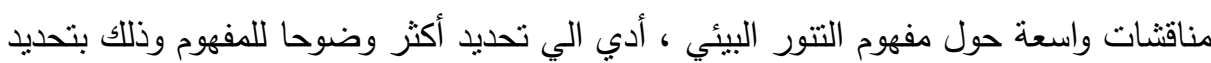
أبعاده ومكوناته المتمثلة في الابعاد اللازمة نوافرها في الفرد لوصفه بالمتتور بيئيا ــ وفي

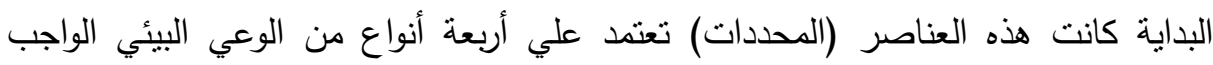

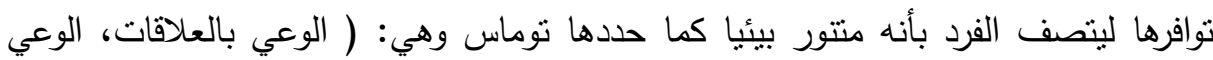
بالسلوكيات، الوعي الحسي، الوعي بالاستهلاك ).

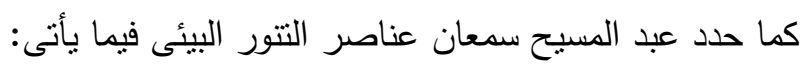
ا ـ معرفة المفاهيم البيئية (المتعلقة بالبيئة الإيكولوجية). r. الوعى بمشكلات البيئة والتربية البيئية. r. الاتجاهات نحو حماية البيئة والتربية البيئية.

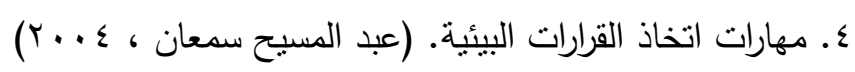

مستويات التنور البيئي: أنثار روث أن للتتور البيئي ثلاثة مستويات وهي ( التتور البيئي الاسمي ( Nominal )،التتور البيئي الوظيفي ( Functional ) ،التتور البيئي السلوكي

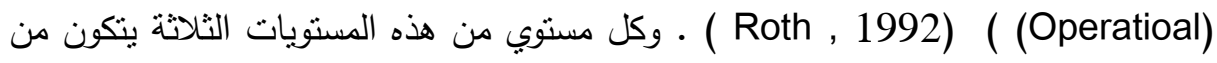

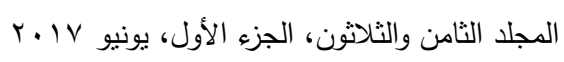


أربعة مستويات فرعية وهي (المعرفة - الإحساس - المهارة - السلوك ) م ففي مستوي التتور البيئي الاول الاسمي ( Nominal )، يكون الفرد قادر علي معرفة مصطلحات ومعاني بالبيئة

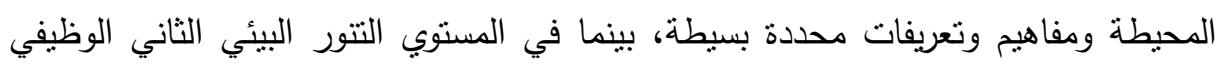
(Functional) عدد قليل من القضايا البيئية ومشكلات بيئنه، بينما في المستوي التتور البيئي الثالث السلوكي

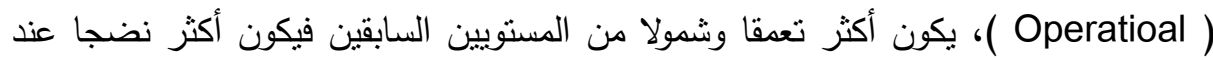

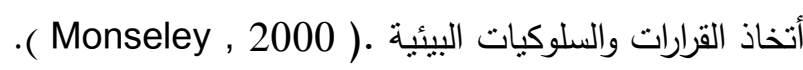

\section{إلبراعايت المهيث}

أولا: إعداد قائمة بالقضايا البيئية( محلية - إقليمية - عالمية). وذلك لتحديد القضايا والمشكلات البيئية اللازمة لتتمية عناصر التتور البيئي لمعلمة رياض الأطفال، قام الباحثون

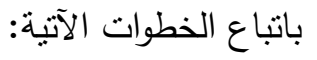

أ- الاستعانة ببعض المراجع والدراسات والبحوث وثثية الصلة بالقضايا والمشكلات البيئية التي يجب أن يكون لمعلمة رياض الأطفال تتور بها وإعداد القائمة بصورة أولية. ب- تم عرض القائمة بصورتها الاولية على محكمين في المناهج ورياض الأطفال والنربية البيئية لاستطلاع آرائهم ومراجعتها لإقرارها. ت- في ضوء ما أبداه السادة المحكمون، أصبحت القائمة في صورتها النهائية معدة لإستخدامها في مجال الدراسة وهي كالتالي:

جدول رقم(1) جائمة القضايا البيئية

\begin{tabular}{|c|c|}
\hline المشكلة الفرعيةً & المشكلة الرئيسية. \\
\hline 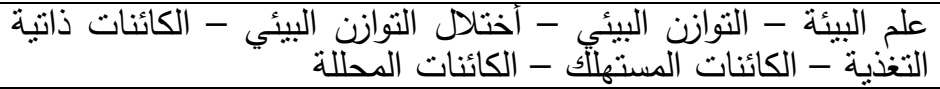 & 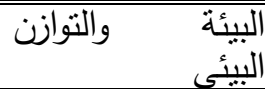 \\
\hline الموارد المتجددة - الموارد الغير متجددة & الموارد الطبيعة \\
\hline تلوث التزبة - تلوث الهواء - نلوث الماء & التلوث البيئ \\
\hline الاحتباس الحراري - تخلخل طبقة الاوزون - الأمطار الحامضية & التغيرات المناخية \\
\hline المشاكل البيئية المتعلقة بنلوث الماء - نلوث نز & مشكلة المياه \\
\hline الرعى الجائر النباتات - انقراض الحيوانات - ازالة الغابات - التصحر - & المشكلات الزراعية \\
\hline
\end{tabular}




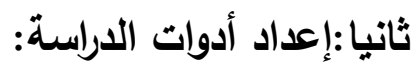

1 - إعداد البرنامج المقترح باستخام الموديولات التعليمية لتنمية عناصر التنور البيئي لاى

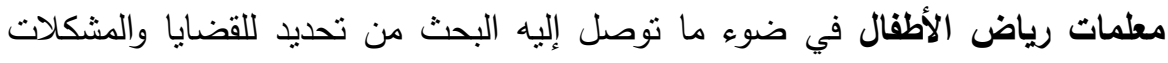
البيئية اللازمة للتتور البيئي لمعلمات رياض الأطفال، قام الباحثون بإعداد أربعة موديولات تعليمية دنضمنة أبعاد بيئية.

• الهلف العام للبرنامج:ويعتبر الهلف العام من البرنامج هو تتمية عناصر التتور البيئي • محتوى البرنامج: وقد روعي في إختيار محتوى البرنامج توافر الثنروط التالتالية:

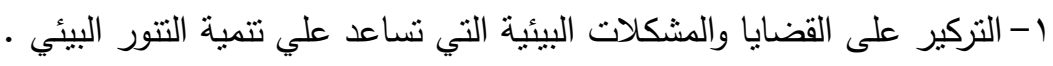

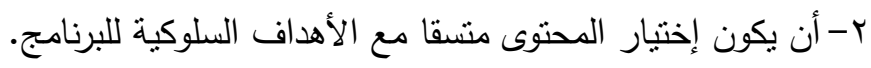
ب- بأن يكون صياغة المحتوى متسلسل ومنطقيا. ع - أن يكون المحتوى انعكاسا فعليا للاحتياجات التربوية في مجال التنور اليبئي. ه- أن يتناسب النثاط المصاحب للمحتوي مع مستوى المتعلمين. تصميم الموديولات التعليمية: تم إعداد وتصميم أربعة موديولات تعليمية بتضمن كل موديول

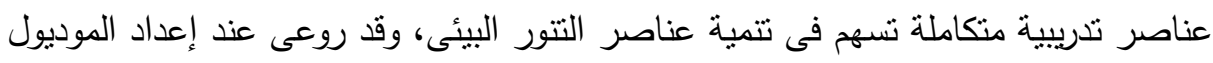

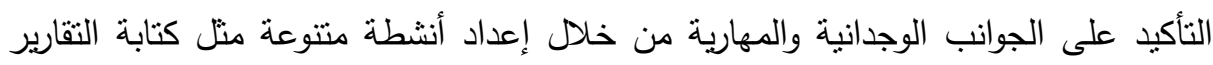

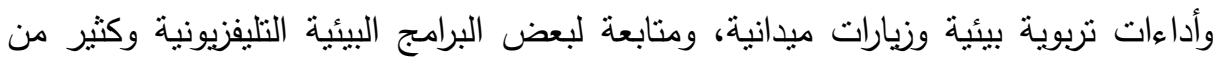

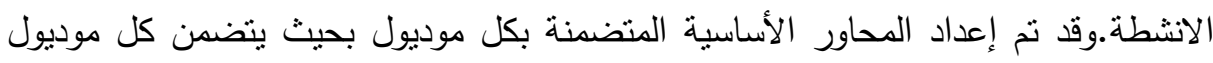

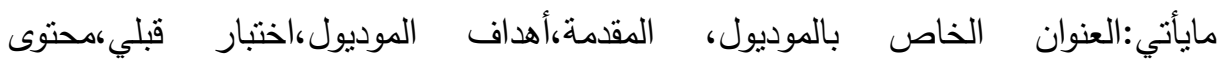
الموديول،تقويم ذاتى وأختبار بعدي،المراجع. الموديول الاول: التتور البيئي وشمل تعريفات عن التنتور البيئي وعلاقة التنربية البيئية بالتتور

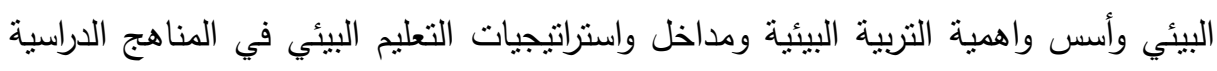

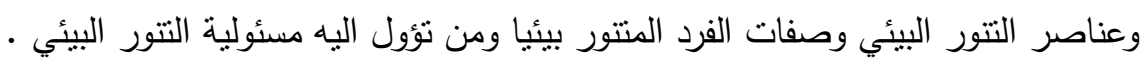

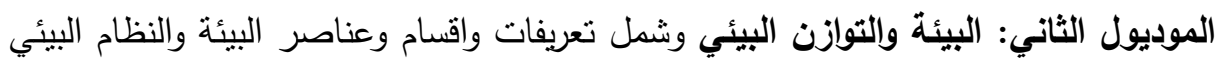

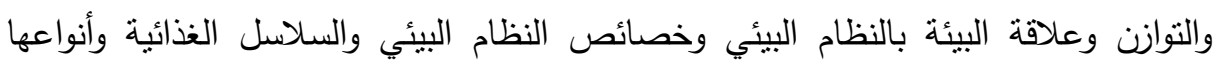

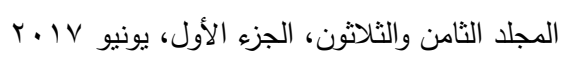


وبعض المشكلات البيئية وكيفية الحد منها وعلاقة الانسان بالبيئة ودوره في مواجهة التحديات

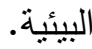

الموديول الثالث : تلوث الهواء وشمل تعريفات تلوث الهواء ومصادر التلوث ومكونات الغلاف الغازي والأثار المترتبة علي التلوث وظاهرة الأمطار الحامضية وطرق الوقاية والتحكم في تلوث الهواء.

الموديول الرابع: تلوث الماء وشمل أهية الماء والمقصود بتلوث الماء وأهم مصادر تلوث

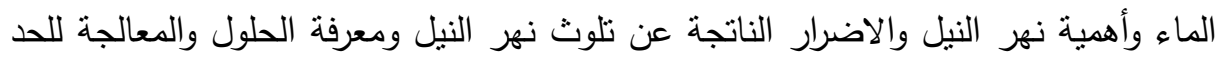
من التلوث المائي. عرض البرنامج على المحكمين:تم عرض الموديولات على مجموعة من المحكمين فى مجال المناهج وتربية الطفل والتربية البيئية،كذلك عرضت عرضت الموديولات على مجموعة من معلمات رياض الأطفال للتعرف على مدى إمكانية التفاعل مع المحتوى العلمي.ثم قام الباحثون بإجراء

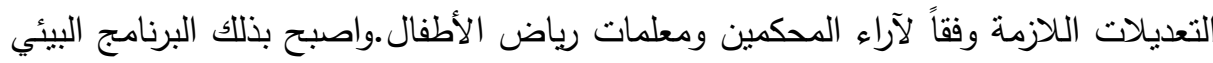
المقترح فى صورته النهائية قابل للاستخدام. r- إعداد مقياس التنور البيئي لمعلمات رياض الأطفال. ولقد تضمن مقياس التتور البيئي

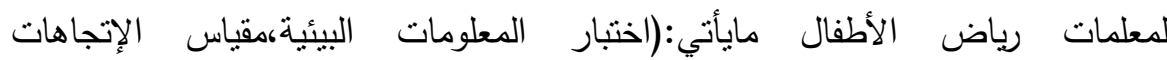
البيئية،مقياس المهارات البيئية).

أ- اختبار المعلومات البيئية: ويهدف إلى قياس مدى معرفة معلمات رياض الأطفال لبعض لئل المعلومات البيئية المرتبطة بقضايا ومشكلات البيئة التي تساعدهم على التتور البيئي، وتم صياغة المفردات حيث شمل الاختبار على أسئلة الاختيار من متعدد (سؤال تليه اربعة

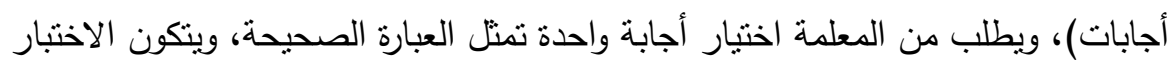

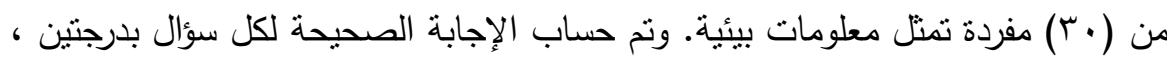

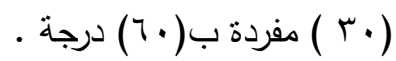

ثبات الأختبار: نم حساب ثنات الاختبار وذللك بعد نطبيقه على ·r معلمة من معلمات رياض

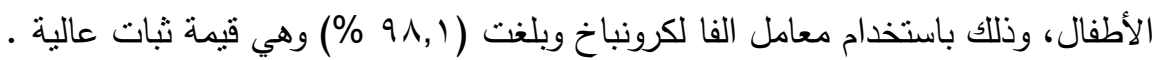


صدق الاختبار: نم عرض الاختبار على مجموعة من المتخصصين لتقويمه وفى ضوء آراء

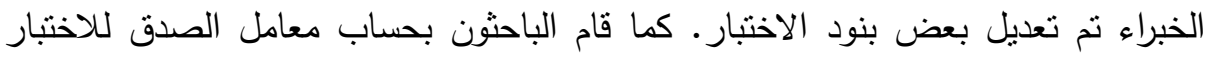

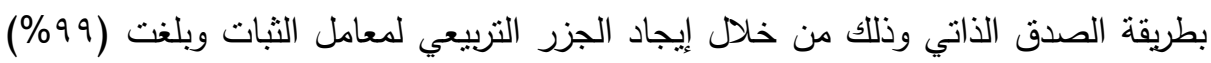

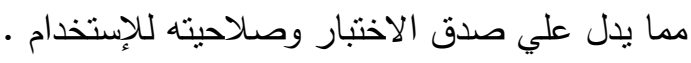

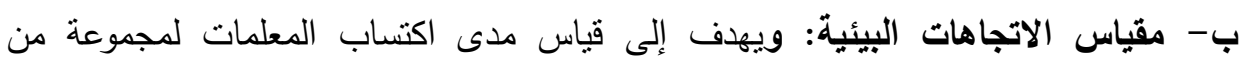
الاتجاهات الايجابية نحو البيئية. وقام الباحث بإعداد وصياغة مواقف المقياس حيث هابث

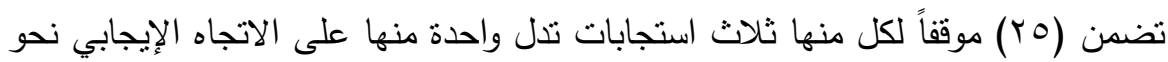

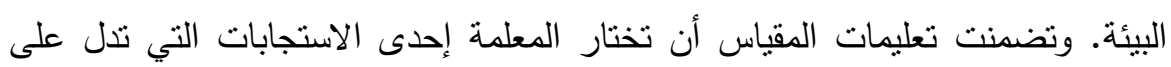

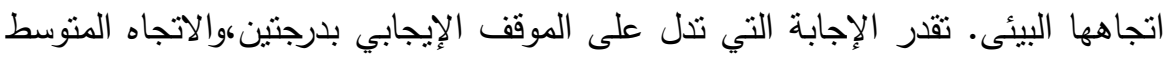

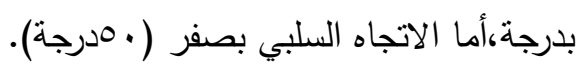

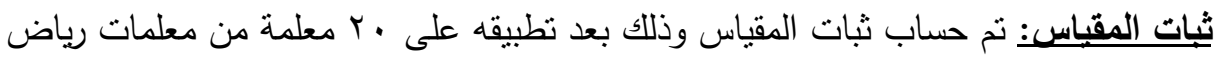

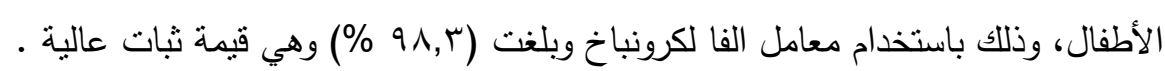
صدق المقياس: تم عرض المقياس على مجموعة من المتخصصين لنقويمه كما قام الباحثون

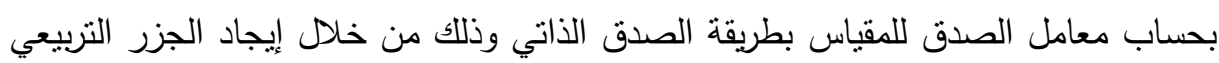

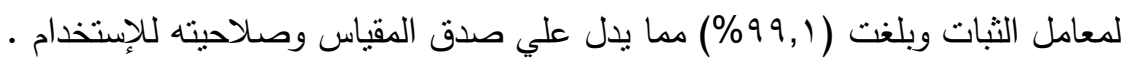

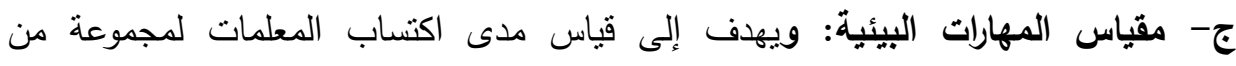

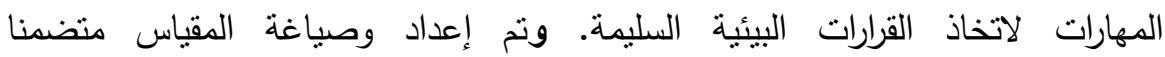
الموضوعات البيئية التي تسهم فى تتمية التتور البيئي التي نم التوصل إليها وتحدث بشكل متكرر فى الروضات، ويطلب من المعلمة تحديد القرار الذى تتخذه فى كل موقف،وينكون من ثلاثة مكونات وتقدر كل مهارة من مهارات اتخاذ القرارات البيئية على كل موقف تتخذ

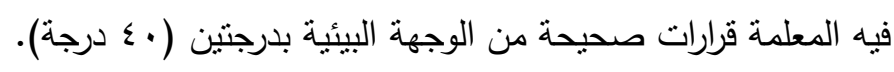

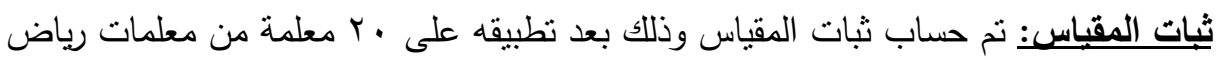

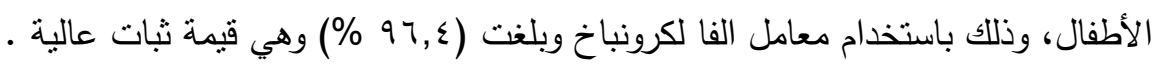


صدق المقياس: تم عرض المقياس على مجموعة من المتخصصين لتقويمه كما قام الباحثون بحساب معامل الصدق للمقياس بطريقة الصدق الذاتي وذلك من خلال إيجاد الجزر التربيعي التهاي لمعامل الثبات وبلغت ( (9^,1\%) مما يدل علي صدق المقياس وصلاحيته للإستخدام. جلول رقم (ץ): يوضح قيم الثبات والصدق لمقياس التتور البيئي لمعلمات رياض الأطفال

\begin{tabular}{|c|c|c|c|c|c|}
\hline معامل الصدق & قيم الثبات & لارجة النهاية العظمي & عدد بنود & مكونات مقياس التنور البيئى & b \\
\hline$\% 99$, . & $\% 9 \wedge, 1$ & 7. & $r$. & اختبار المعلومات البيئية & 1 \\
\hline$\% 99,1$ & $\% ৭ \wedge, r$ & o. & ro & مقياس الاتجاهات البيئة & r \\
\hline$\% ৭ \wedge, 1$ & $\% 94, \varepsilon$ & $\varepsilon$. & $r$. & مقياس المهارات البيئية & $r$ \\
\hline$\% ৭ \wedge, \vee$ & $\% 9 \vee, 7$ & 10. & vo & مقياس التنور البيئي (ككل) & \\
\hline
\end{tabular}

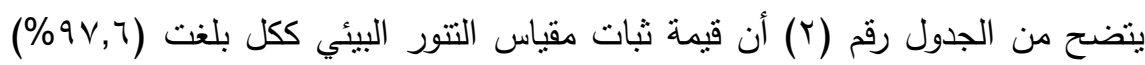

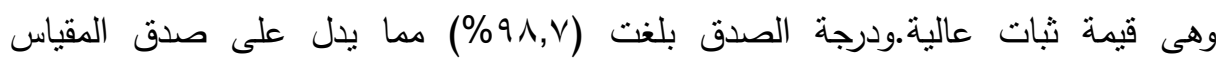
وصلاحيته للاستخدام. • الصورة النهائية لمقياس التنور البيئي لمعلمة رياض الأطفال:بعد أن تحقق الباحث من صدق وثبات المقياس أصبح المقياس فى صورته النهائية يتكون من (Y0) بنداً، والنهاية العظمى للمقياس( • 10) درجة كما هو موضح في الجدول السابق رقم (Y). r- - إعداد مقياس السلوك البيئي لأطفال الروضة التي تقوم المعلمات بتقديم الأنشطة لهم

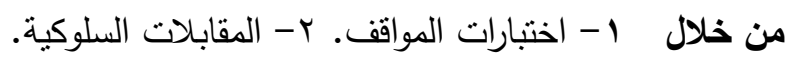

ا-اختبار المواقف: ويهذف الاختبار للتعرف على مدى توافر السلوكيات البيئية لدى أطفال الروضة التي تقوم المعلمات عينة البحث بتقديم الانشطة لهم.تمت صياغة مفردات الاختبار في صورة مجموعة من التساؤلات المرتبطة بمواقف وممارسات وأنشطة بيئية ينبغي القيام بها أو عدم القيام بها حيث يوضح أمام كل سؤال اختيارين (أفعل / لا أفعل).

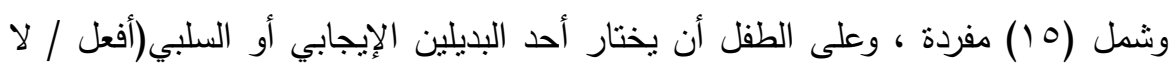

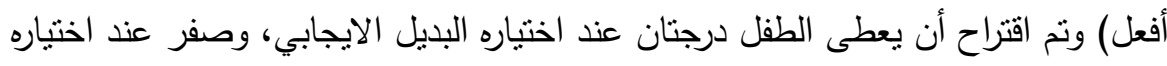
البديل السلبي. وبذللك تكون الدرجة النهائية (•r) درجة اندئ. 
r-المقابلات السلوكية: من أكثر وسائل قياس السلوك استخداما، وهي تتبه المقابلات

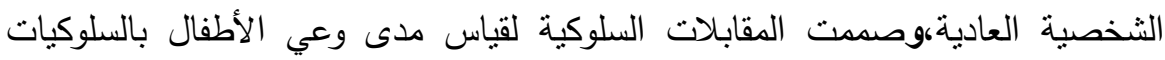

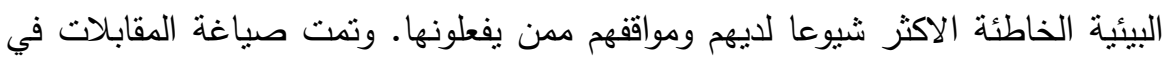
صورة مواقف مصورة بالفيديو على الأطفال ثم نطبيق الاختبار بنظام المقابلة السلوكية

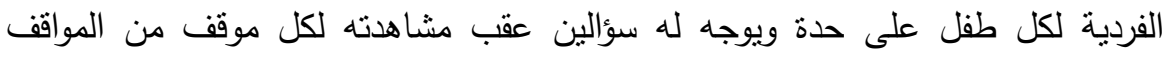

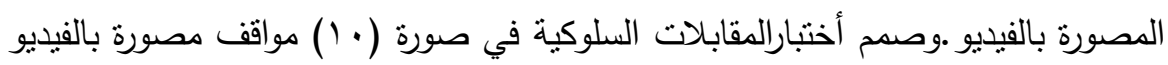
تعرض على الأطفال ثم يوجه لكل طفل على حدة سؤالين عقب مشاهدته لكل موقف من المواقف المصورة بالفيديو .وتم اقتراح أن يعطى الطفل درجة واحدة عند إجابته عن السؤال الاول اجابة صحيحة وصفرا دون ذلك، كما يعطى درجة واحدة عندما يكون موقفه إيجابيا

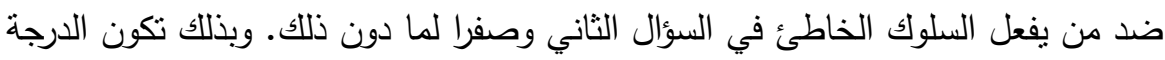

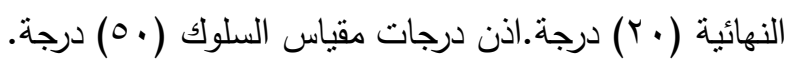
• ثبات اختبار تقويم السلوك:اختار الباحث "طريقة كوبر" لحساب ثبات اختبارتقويم السلوك، وتتلخص بقيام اثثين من الملاحظين بقياس ثبات الاختبار فقام بتسجيل مدى اكتساب

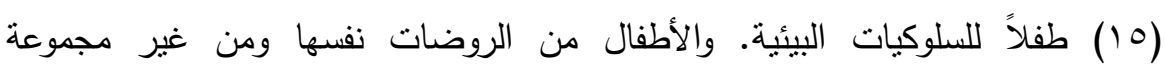
البحث.ومعامل ثنات الاختبار هو نسبة الارتباط بين الدرجنتين التي يعطيها ملاحظين مختلفين، ونم حساب نسبة الثبات (نسبة الاتفاق) باستخدام نسبة الاتفاق لكوبر .

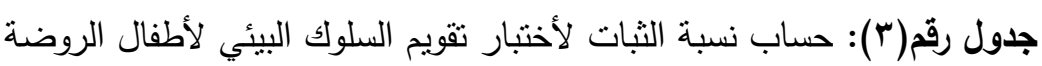

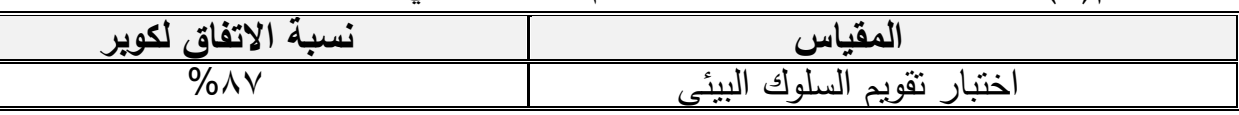

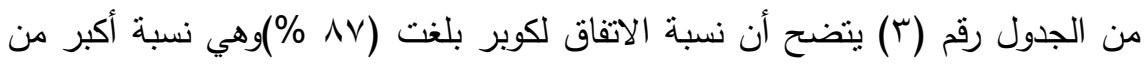

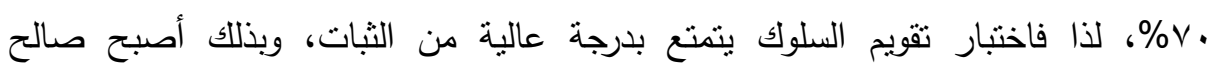
لاستخدام. • صدق اختبارتقويم سلوك: لقد قام الباحث بالتحقق من الصدق المنطقي لاختبار تقويم

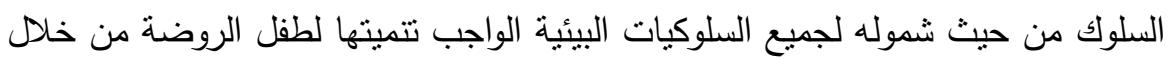

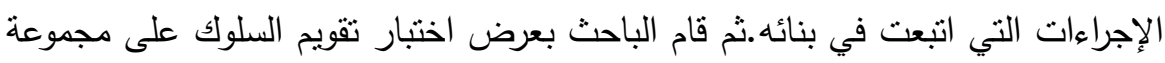


من الخبراء في المناهج وتربية الطفل والتربية البيئية وذلك بهدف أخذ أرائهم،ولقد أدت آراؤهم إلى إجراء تعديلات في بعض بنود أختبارتقويم السلوك، ثم إعادة صياغته بالثكل

$$
\text { ع - الذي يحقق الهدف الذي وضع لأجله. }
$$

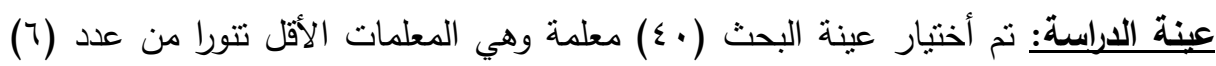

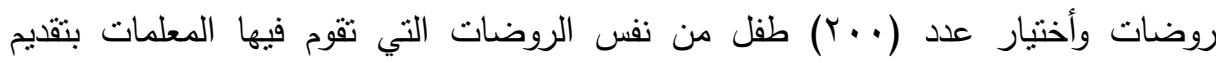
الانشطة لهم كما هو موضح في الجدول التالي:

\begin{tabular}{|c|c|c|c|}
\hline (المشاركين الآطفال) & (عينة المعلماتة & أسم الروضة & b \\
\hline$\varepsilon$. & 1. & روضة سان جورج بالمعتمدية & 1 \\
\hline$\varepsilon$. & V & روضة مارينا النموذجية بالوراق & $r$ \\
\hline$r$. & $r$ & روضنه مريم بالوراق & $\bar{r}$ \\
\hline$r$. & 0 & روضه سان استفانو برستم & $\varepsilon$ \\
\hline$\varepsilon$. & V & روضه سانت ماري ببهنتيم & 0 \\
\hline$\varepsilon$. & $\Lambda$ & روضها دمبانة ببيجام & 7 \\
\hline r. & $\varepsilon$. & الاجمالي & \\
\hline
\end{tabular}

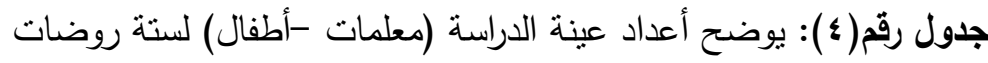

• أثالثا : خطوات تطبيق الاراسة:

ا ـ نطبيق مقياس التتور البيئي (معلومات - اتجاهات - مهارات) للتعرف على مستوى التتور

$$
\text { البيئي الحالي لديهن. }
$$

r. تجريب البرنامج البيئي المقترح لتتمية عناصر التتور البيئي على معلمات رياض الأطفال الأقل تتوراً (عينة البحث) من خلال الموديولات الاربعة المختلفة.

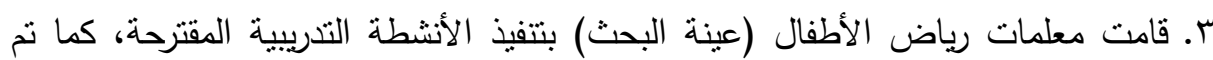
استخدام تدريبات تطبيقية ينم استخدامها فى قاعات الأنشطة مع الأطفال واستغرق تتفيذ النال البرنامج التدريبى المقترح اثثى عشر أسبوعا. ع. تم مناقثة الأنشطة التدريبية المتضمنة فى البرنامج التدريبي، وتبادل الخبرات بين التبرع المعلمات، وتتفيذ ورش عمل لتتمية بعض عناصر التتور البيئي. 


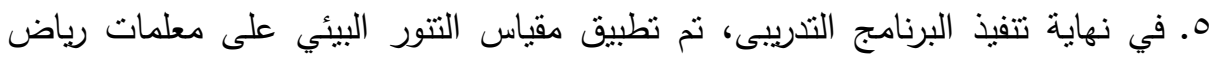
الأطفال (عينة البحث) نطبيقاً بعدياً بعد انتهاء آخر معلمة من دراسة البرنامج المقترح 7. ومن ثم قام الباحثون بتجميع البيانات ورصد الدرجات وتحليلها ومعالجتها إحصائيا تمهيدا

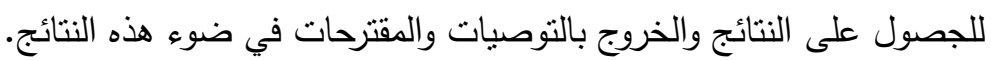

\section{نمائج القراسة}

- أولاً: نتائج الدراسة قبلياً: نم تطبيق مقياس التتور البيئي (معلومات - إتجاهات مهارات) على أفراد العينة المكونة من ·ـ من معلمات رياض الأطفال وتم رصد النتائج

$$
\text { وتحليلها. وكانت النتائج كالتالي: }
$$

جلول رقم(ه): يوضح النسب المئوية لمجموع الدرجات التي حصلت عليها معلمات رياض

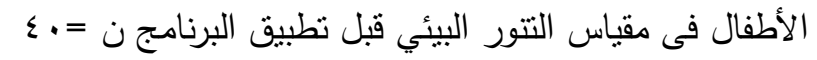

\begin{tabular}{|c|c|c|c|c|}
\hline \multicolumn{2}{|c|}{ قبلى (ن ع } & \multirow[b]{2}{*}{ درجة المقياس } & \multirow[b]{2}{*}{ أبعاد مقياس التتور البيئى } & \multirow[b]{2}{*}{ b } \\
\hline النسبة المئوية & مجموع الدرجات & & & \\
\hline$\%$ \%ई, r० & 99. & 7. & اختبار المعلومات البيئية & 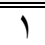 \\
\hline$\% \leftrightarrow q, q$ & V9V & 0. & مقياس الاتجاهات البيئة & r \\
\hline$\% r \varepsilon, 7$ & $00 \leqslant$ & $\varepsilon$. & مقياس المهارات البيئية & $r$ \\
\hline$\% \curlyvee \wedge, 0 \wedge$ & $r T \leqslant 1$ & 10. & اجمالي مقياس التتور البيئُ & \\
\hline
\end{tabular}

يوضح الجدول رقم (0) إلى تدني مسنوى التتور البيئي (معلومات - اتجاهات -

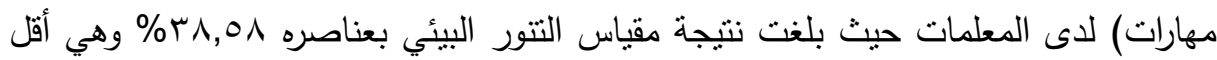
من حد الكفاية للتنور البيئي (\%o\% من مجموع الدرجات). مما يشير إلى انخفاض مستوى التتور البيئي لاى معلمات رياض الأطفال.أما بالنسبة لعناصر التتور البيئي (معلومات -

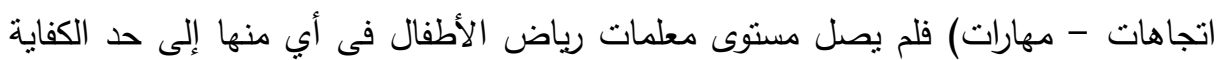
والتنور •

ثانيا: تنفيذ البرنامج: بعد ذلك تم تتفيذ البرنامج بتطبيق أربعة موديولات تعليمية وفقا

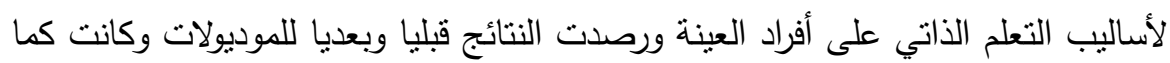
هي موضحة في الجدول التالي: 
جدول( آ): يوضح الفرق بين التطبيق القبلي والبعدي للموديولات التعليمية

\begin{tabular}{|c|c|c|c|c|c|c|}
\hline \multirow{2}{*}{ الالالئة } & \multirow{2}{*}{ قَيمة } & \multicolumn{2}{|c|}{ التطبيق البعدي (ن) } & \multicolumn{2}{|c|}{ التطبيق القبلّي } & \multirow{2}{*}{ اسم الموديول } \\
\hline & & $r \varepsilon$ & $r_{p}$ & lع & م & \\
\hline دال & $0,10$. & 11,271 & $r 0,7$. & $7, .7 V$ & $\overline{r r, T .}$ & البيئي \\
\hline دال & $r \varepsilon, 1 \wedge \varepsilon$ & Y,M & $\varepsilon 7, \cdot V$ & $0, .90$ & $r \leqslant, T V$ & البيئة والتوازن البيأ \\
\hline دال & $r 7,109$ & $1,97 \pi$ & $\sum 7,1 Y$ & $0, \cdot \leqslant 1$ & $r \mu, 10$ & تلوث الهواء \\
\hline دال & $0,9 \vee V$ & $11, r \circ Y$ & $r 7, .0$ & $\varepsilon, 77 \wedge$ & $r \varepsilon, \varepsilon 0$ & تلوث الماء \\
\hline
\end{tabular}

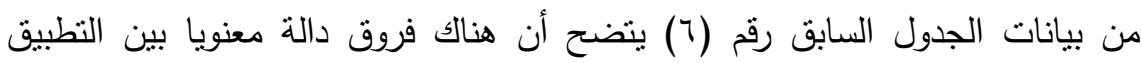

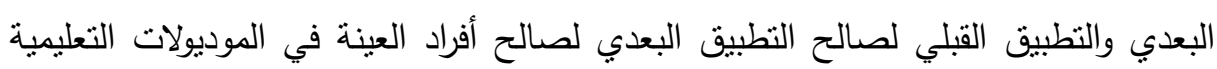
الاربعة.

ثالثا: التطبيق بعديا لمقاييس التنور البيئي: بعد تطبيق البرنامج ودراسة الموديولات الاربعة لعينة الدراسة ، تم تطبيق مقياس التتور البيئي على أفراد العينة بعديا ثم حساب لئي

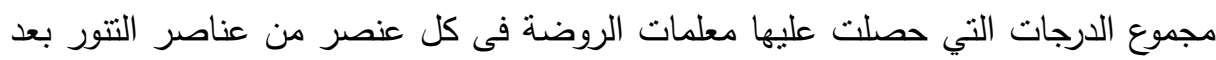
تطبيق البرنامج، وحساب النسب المئوية لها كما هو موضح في الجدول الثالي:

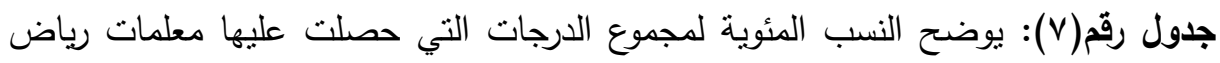

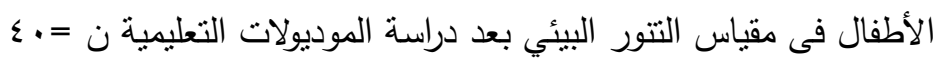

\begin{tabular}{|c|c|c|c|c|}
\hline \multicolumn{2}{|c|}{ بعدى (ن · \&) } & \multirow{2}{*}{ درجة المقياس } & \multirow{2}{*}{ أبعاد مقياس التنور البيئى } & \multirow[b]{2}{*}{ b } \\
\hline النسبةٌة المئويةٌ & مجموع الارجات & & & \\
\hline$\% \wedge \Upsilon, \vee$ & $\overline{r \cdots \Lambda}$ & 7. & اختبار المعلومات البيئية & 1 \\
\hline$\% \wedge r, \varepsilon$ & $17 \varepsilon \Lambda$ & 0. & مقياس الاتجاهات البيئة & $\mu$ \\
\hline$\% \wedge \Sigma, 0$ & ITOY & ६. & مقياس المهارات البيئية & $\varepsilon$ \\
\hline \%रץ,Oץ & 0.11 & 10. & اجمال مقباس التتور البئي & \\
\hline
\end{tabular}

يتضح من الجدول السابق رقم (V) ارتفاع مستوى التتور البيئي لدى المعلمات بعد دراسة

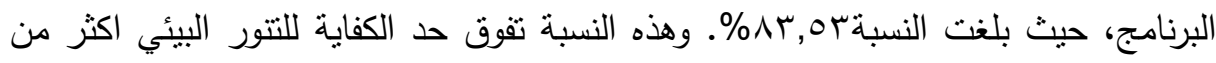

$$
\begin{aligned}
& \text { (\%>0) } \\
& \text { • جدوى البرنامج وفعاليته. }
\end{aligned}
$$


• يوكد على ارتفاع مستوى معلمات رياض الأطفال فى كل عناصر التتور البيئي (معلومات

- اتجاهات - مهارات) بما يفوق حد الكفاية. وذلك يدل على فعالية البرنامج المقترح. رابعاً: لاختبار صحة الفروض: لأختبار صحة الفروض تم حساب المتوسطات، والانحرافات المعيارية للارجات التي حصل عليها معلمات رياض الأطفال في مقياس التتور البيئي قبل، وبعد تطبيق البرنامج، ثم حساب قيمة (ت) للتعرف على دلالة الفروق بين

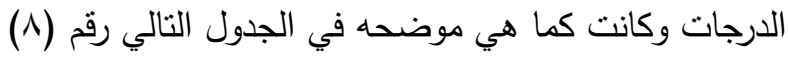
جدول(^): يوضح الفرق بين بين النطبيق القبلي والتطبيق البعدي لمقياس التتور البيئي

\begin{tabular}{|c|c|c|c|c|c|c|c|}
\hline \multirow{2}{*}{ الدالئةي } & \multirow{2}{*}{ قيمة } & \multicolumn{2}{|c|}{ التطبيق البعدئ } & \multicolumn{2}{|c|}{ التطبيق القبلى } & \multirow{2}{*}{ المقيَّس } & \multirow{2}{*}{ أبعاد البيئس } \\
\hline & & $r \varepsilon$ & $r_{p}$ & iह & م1 & & \\
\hline$\cdot, \cdots l$ & $17, \Sigma \Gamma$ & 0,09 & $0 ., Y$. & $\Lambda, \cdot r \leq$ & $r \leqslant, V 0$ & 7. & الينتبار المعلومات \\
\hline$\cdot$, & $1 \mathrm{~V}, 07$ & $r, \leqslant\rceil$ & $\varepsilon 1, Y$. & 7,10 & $19, \wedge \mathrm{V}$ & 0. & مقياس الاتجاهات حماية البيئة \\
\hline 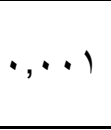 & 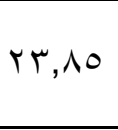 & $r, \wedge \vee$ & rT, & $\varepsilon, \varepsilon \Gamma$ & $1 \%, q$. & $\varepsilon$. & الخاذي $\quad$ البيئة \\
\hline$\cdot, \cdots l$ & $r 1,10$ & $11, \varepsilon V$ & To & $|7, r|$ & ON,OY & 10. & التتور البيئى مقياس \\
\hline
\end{tabular}

1-للتحقق من صحة الفرضية الاولى: تم حساب المتوسطات، والانحرافات المعيارية للارجات التي حصل عليها معلمات رياض الأطفال في مقياس التتور البيئي ككل (معلومات - اتجاهات - مهارات) قبل وبعد تطبيق البرنامج، ثم حساب قيمة (ت) للتعرف لهات عل دلالة الفروق بين الدرجات وكانت كما هي موضحة في الجدول السابق رقم (^)، يوضح أن هنالك فروق دالة معنويا بين التطبيق البعدي والتطبيق القبلي لصالح التطبيق

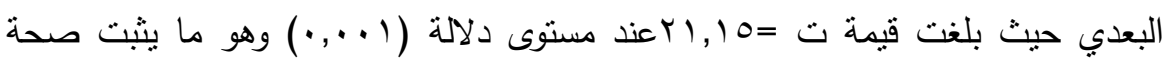

$$
\text { الفرضية الاولي }
$$

r-للتحقق من صحة الفرضية الثانية: نم حساب المتوسطات، والانحرافات المعيارية للارجات التي حصل عليها معلمات رياض الأطفال في أختبار المعلومات البيئية قبل، وبعد تطبيق البرنامج، ثم حساب قيمة (ت) للتعرف على دلالة الفروق بين الدرجات وكانت

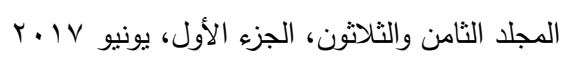


كما هي موضحه في الجدول السابق رقم (^) يوضح أن هناك فروق دالة معنويا بين

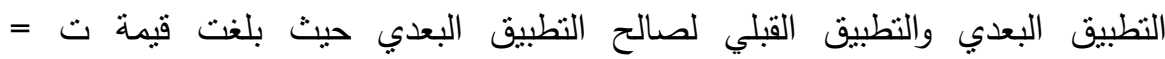

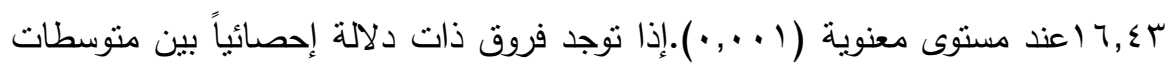
درجات معلمات رياض الأطفال فى أختبار المعلومات البيئية قبل وبعد دراسة البرنامج المقترح لصالح التطبيق البعدي وهو ما يثبت صحة الفرضية الثانية. r-للتحقى من صحة الفرضية الثالثة: نم حساب المتوسطات، والاتحرافات المعيارية للارجات بنات التي حصل عليها معلمات رياض الأطفال في مقياس الاتجاهات البيئية قبل، وبعد نطبيق

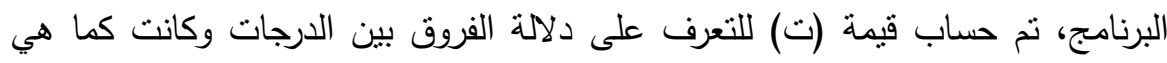
موضحه في الجدول السابق رقم (^) يوضح أن هناك فروق دالة معنويا بين النطبيق

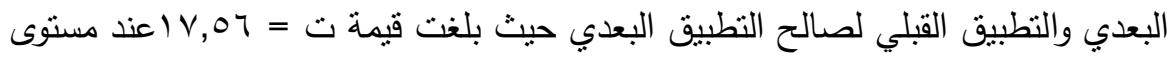
معنوية (1 ..,.•).إذا توجد فروق ذات دلالة إحصائياً بين متوسطات درجات معلمات

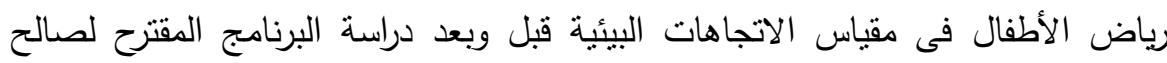
التطبيق البعدي وهو ما يثبت صحة الفرضية الثالثة.

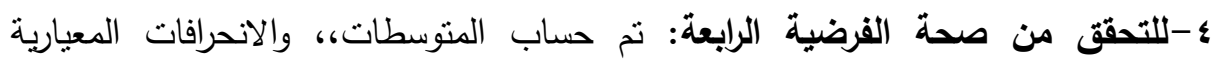

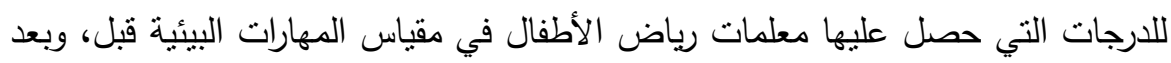
تطبيق البرنامج ، ثم حساب قيمة (ت) للتعرف على دلالة الفروق بين الدرجات وكانت كما هي موضحه في الجدول السابق رقم (^)هيوضح أن هناك فروق دالة معنويا بين النطبيق

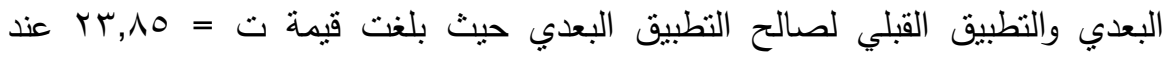

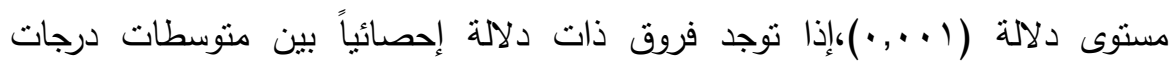

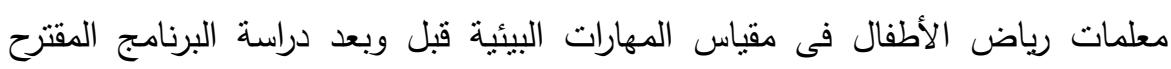

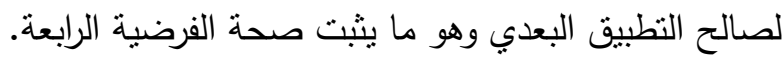

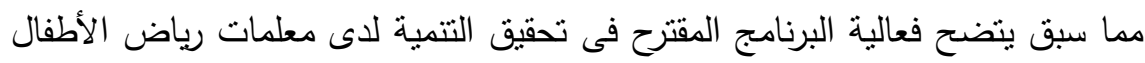

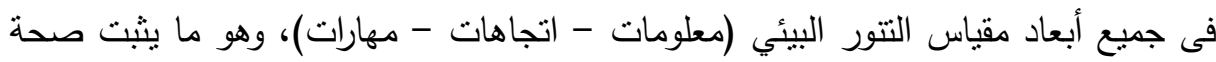
الفرضية الرابعة. 
• قياس فعالية برنامج التنور البيئي المقترح:للتعرف على فعالية برنامج التتور البيئي المقترح، قام الباحث بحساب نسبة الكسب المعدل لبلاك، ويوضح الجدول الآتى ذلك: جدول رقم(9) : يوضح نسبة الكسب المعدل لبلاك

\begin{tabular}{|c|c|c|c|c|}
\hline التاثير & المعبة الكبل البذب & اللارقيأية & متوسطة درجات مقياسليات & متوسطة فرجات مقياسيات \\
\hline مقبولة & $1,1 \mathrm{~V}$ & 10. & IYO,YO & $0 \Lambda, 0 Y$ \\
\hline
\end{tabular}

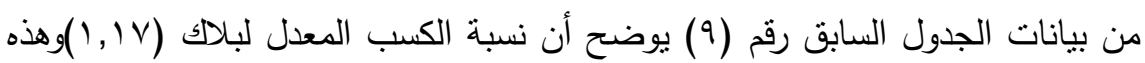
قيمة تقع فى المدى الذى حدده بلاك للفعالية (1-r) وهو ما بشير إلى فعالية البرنامج المقترح

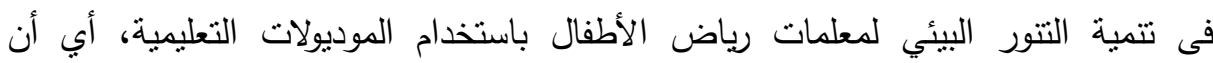

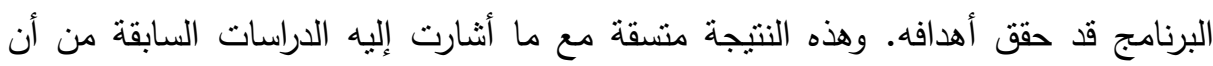
إعداد البرامج البيئية يساعد فى تتمية التتور البيئي لادى المعلمين.

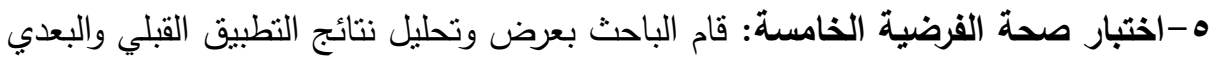

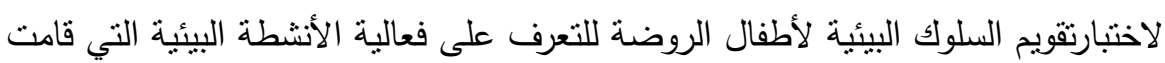

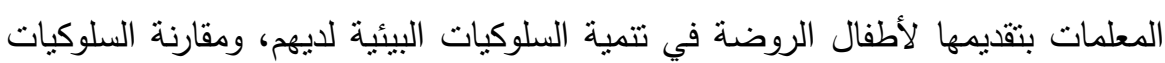

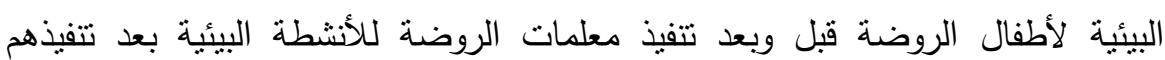
للبرنامج، وحساب المتوسطات، والانحرافات المعيارية للارجات التي حصل عليها أطفال الروضة فى اختبارتقويم السلوك قبل وبعد تتفيذ معلمات رياض الأطفال للبرنامج، ثم قيمة (ت) للتعرف على دلالة الفروق بين الدرجات.ويوضح الجدول التالى متوسط الدرجات التي لتصني

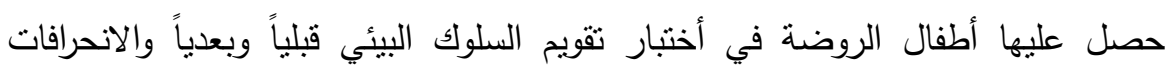

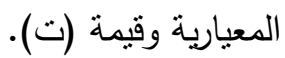

جدول رقم( • 1): يوضح متوسطات الدرجات التي حصل عليها أطفال الروضة فى اختبارتقويم

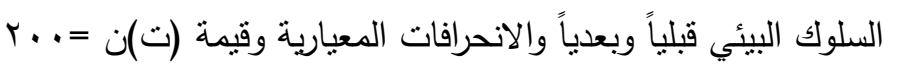

\begin{tabular}{|c|c|c|c|c|c|c|}
\hline \multirow{2}{*}{ الفروق } & \multirow{2}{*}{ ت } & \multicolumn{2}{|c|}{ بعدى } & \multicolumn{2}{|c|}{ قبلى } & \multirow{2}{*}{ درجة المقياس } \\
\hline & & $r \varepsilon$ & $r_{p}$ & $1 \varepsilon$ & 18 & \\
\hline$\cdot, \cdots)$ & $\varepsilon \neg, Y\rceil$ & $r, r \cdot q$ & $\varepsilon 0, V T$ & $T, r \cdot V$ & $r \varepsilon, 1 V$ & 0. \\
\hline
\end{tabular}

$$
\text { المجلد الثامن والثلاثون، الجزء الأول، يونيو V r. r }
$$


من بيانات الجدول السابق رقم (• () يتضح أن هناك فروق دالة معنويا بين التطبيق

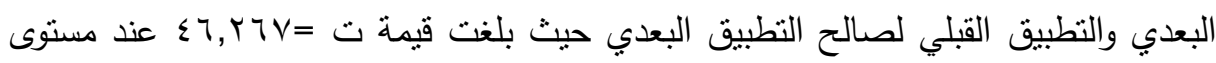
دلالة ا +.., · وهو مايثبت صحة الفرضية الخامسة.

$$
\text { تعليق على النتائج: }
$$

• من النتائج يتضح أن دراسة معلمات رياض الأطفال لبرنامج التتور البيئي المقترح

باستخدام الموديولات التعليمية قد اثبت فعاليته في تتمية عناصر التتور البيئي لدى هؤلاء المعلمات.

• كذلك تتمية عناصر التتور البيئي لمعلمات رياض الأطفال ساهم فى تتمية السلوكيات

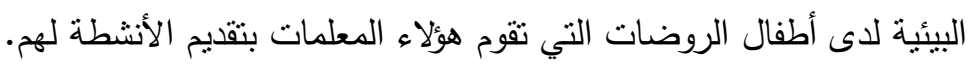

\section{تموسياهت المهيث}

فى ضوء ما توصلت إليه الدراسة من نتائج، يمكن تقديم التوصيات الآتية: ا • ربط المقررات الدراسية لجميع المراحل التعليمة بالبيئة المحيطة.

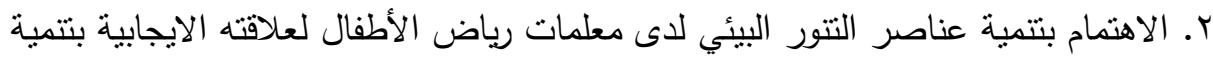

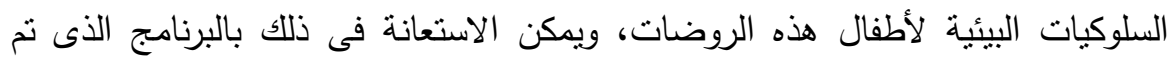

$$
\text { إعداده فى هذه الدراسة. }
$$

r. مراجعة البرامج الحالية لمعلمات رياض الأطفال وتضمين عناصر التتور البيئي فى البرامج

$$
\text { المقترحة وتطبيقها. }
$$

ع. تضمين عناصر النتور البيئي في مناهج كليات رياض الأطفال.

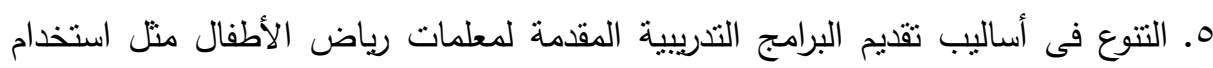
أسلوب التعلم الذاتى، والاهتمام بالأنشطة التدريبية كالزيارات والرحلات البيئية لما لها من لئن

$$
\text { أثز فى تتمية المهارات والسلوكيات البيئية المرجوة. }
$$

7. الاهتمام بتدريب معلمات رياض الأطفال على استخدام استراتيجيات تعلم مناسبة لتعديل

$$
\text { السلوكيات البيئية الخطأ لدى أطفال الروضة. }
$$




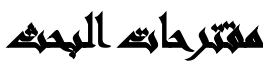

في ضوء هذه الدراسة يقترح الباحثون الاتي:

1. عمل دراسات أخري مشابهة في التتور البيئي لاى روضات الاتهي أخري كالصعيد، ومجتمعات

$$
\text { اخري عربية خارج مصر للوقوف على الجوانب المختلفة. }
$$

r. دراسة تقويمية للتعرف على مدى توافر عناصر التتور الييئي لدى أولياء امور أطفال

$$
\text { الروضة. }
$$

r. دراسة تقويمية للتعرف على مدى توافر عناصر التتور البيئي لدى طالبات كلية رياض

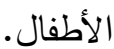

ع. فعالية استخدام استراتيجية التعلم التعاونى فى تعديل السلوكيات البيئية الخطأ لاى أطفال

$$
\text { الروضة. }
$$

\section{zall}

احمد حسين اللقاني(ب99 (1): البيئة والمناهج المدرسية، مركز الكتاب للنشر، القاهرة.

أحمد حسين اللقاني، على الجمل(999 (1). معجم المصطلحات التربوية المعرفة في المناهج وطرق التدريس، الطبعة الثانية. القاهرة، عالم الكتب.

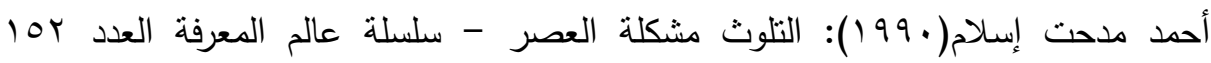
يصدرها المجلس الوطني للثقافة والفنون والاداب.

حسن شحاته(79 99 (): قراءات الأطفال، الدار المصرية اللبنانية، الطبعة الثالثة، القاهرة.

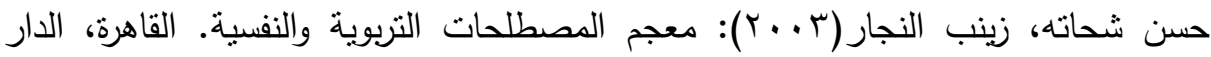

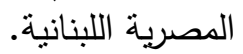

الدمرداش عبد المجيد سرحان(9919). المناهج المعاصرة ، الكويت ، مكتبة الفلاح للنشر والتوزيع.

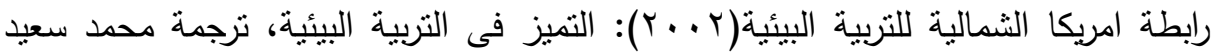

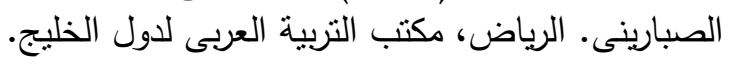

سهير كامل احمد. سيكولوجية نمو الطفل، مركز الاسكندرية للكتاب، الاسكندرية، 999 19.

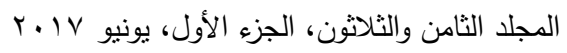


صبرى الدمرداش، محمد دسوقى(990 (): الاتجاهات البيئية لدى طلاب كليات التربية فى الإى

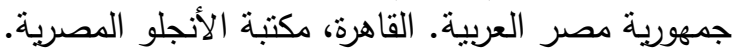

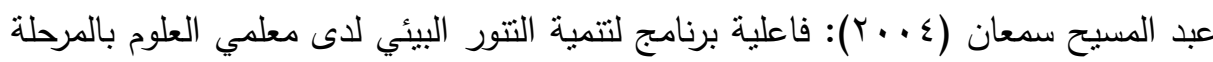

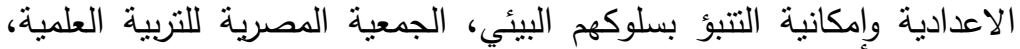
مجلة التربية العلمية، المجلد السابع، العدد الثاني.

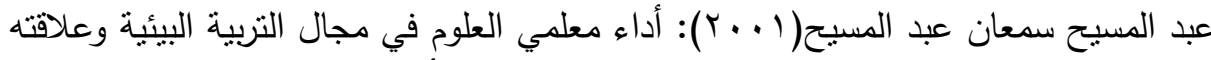
بالوعي البيئي لدى تلاميذهم بمرحلة التعليم الأساسي، مجلة التربية العلمية.

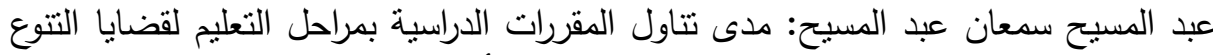

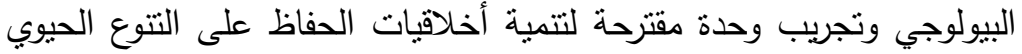

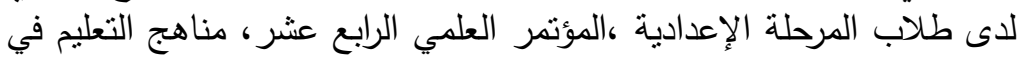

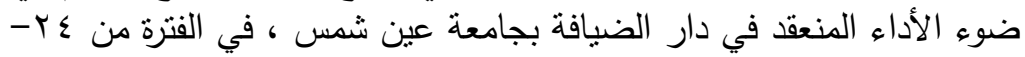

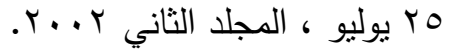

عواطف إبراهيم محمد( ... ب): الطرق الخاصة بتربية الطفل وتعليمه في الروضة. القاهرة،

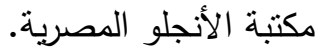

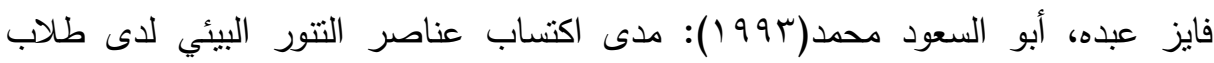
المرحلة الثانوية، مجلة دراسات فى المناهج وطرق التدريس.

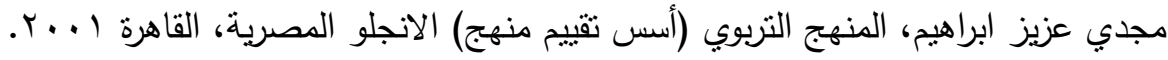

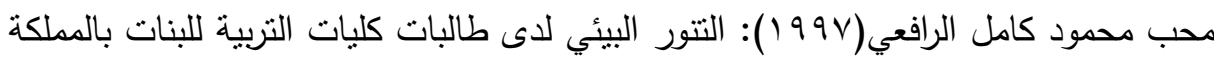
العربية السعودية ، التربية المعاصرة.

محب محمود كامل الرافعي(؟ . ب): التربية البيئية من أجل بيئة أفضل. القاهرة، المركز القومي للبحوث التربوية والتتمية.

محسن حامد فراج( · . ب): تتمية بعض عناصر التتور البيئي لدى طلاب كلية التربية جامعة

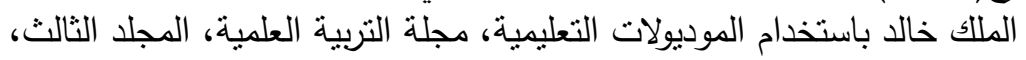

العدد الأول (مارس). القاهرة، الجمعية المصرية للتربية التعلية العلمية. محمد صابر سليم وأخرون(999 (199): مرجع في التربية البيئية للتعليم النظامي وغير النظامي. محمد عبد الفتاح القصاص(ب99(1): الإنسان وقضايا البيئية، معهد البحوث والدراسات

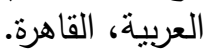


محمد على نصر ( . . ץ): التربية البيئية واعداد المعلم في عصر المعلومانية المؤتمر العلمي

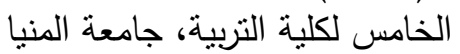

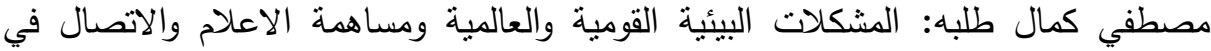
مواجهتها، مجلة النيل، الهيئة العامة للاستعلامات العدد ـع القاهرة . 199

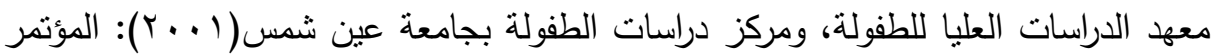

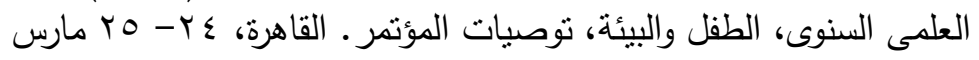

منى محدد على جاد(ع ـ ـ ץ): التربية البيئية في رياض الأطفال، تخطيطها ـ تتفيذها وتقويمها.

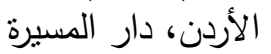

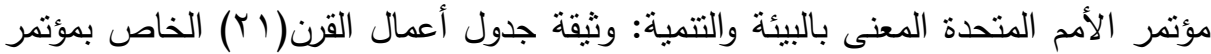

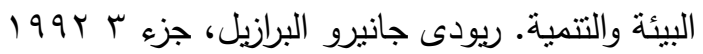

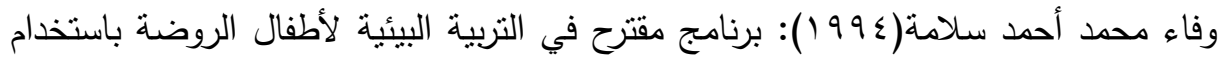

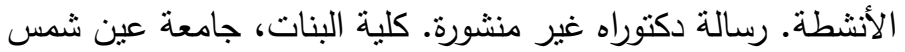

Are, Eve- Marie (2000): Curriculum for Young Children; An Introduction. New York, Delmar.

Briggs, Pamela S.; Pilot, Theo L., and Bagby, Janet H.(2001): Early Childhood Activities for Creative Educators. New York, Delmar.

Charuvil, Chacko \&Chacko, Padeettathi (2001): The Nature and Measurement of Environmental Literacy for Sustainability, University of South Africa.

Coakes, Sheridan \& Steed, Lyndall (2001): SPSS Analysis. Australia, Milton Ltd.

Disinger, John (1992): Environmental Literacy, ERIC, Office of Educational Research and Improvement (ED).

Disinger, John (2001): K-12 Education and the Environment;Perspectives, Expectations and Practice, Journal of Environmental Education, Vol. 33, No.1, PP. 411.

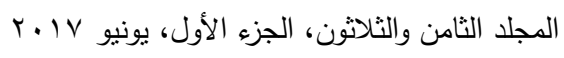




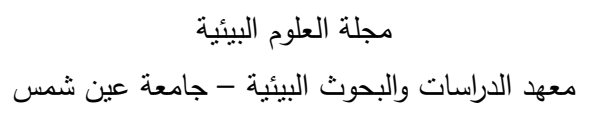

Evers, T. (2011). Wisconsin's plan to advance education for environmental literacy and sustainability in PK-12 schools. Madison: Wisconsin Department of Public Instruction.

Fisher, Bobbi (1998): Joyful Learning in Kindergarten, Revised Edition, New York, Heinemann.

Gayford, G. (2002): Environmental Literacy; Towards a Shared Understanding for Science Teachers, Journal of Research in Science and Technological Education ,Vol.20 , No. 1, PP. 99-110.

Kentucky Environmental Education Council (2005): Annual Report. Kentucky Environmental Education Council.

Krogh, Suzanne L. and Slentz, Kristine L. (2001): The Early Childhood Curriculum. London, Lawrence Erlbaum Associates.

Mckeown, Rosalyn (2000): A Survey of Pre-service Teacher Education Programs, Journal of Environmental Education, Vol. 32, No. 1, P. 4.

Quammen, David (1994): Ecological Literacy in the Wonder Years, Journal of Outside, Vol. 19, No.8, PP. 40-42.

Roth, Charles (1992): Environmental Literacy; Its Roots Evolution and Direction in the 1990's Education Development Center. Newton, Massachusetts, P.1.

UNESCO / UNEP (1985): Environmental Education Module for inservice training of Teachers and Supervisors for Primary School, Environmental Education Series, No.6 , P. 13.

UNESCO / UNEP (1989): Environmental Literacy for all, Vol. 19, No. 2, P.1.

University of Wisconsin, College of Natural Resources (2004): NABE Conference. 


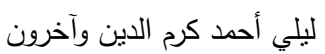

\title{
DEVELOPMENT OF ENVIRONMENTAL LITERACY \\ OF THE KINDERGARTEN FEMALE TEACHERS \\ USING EDUCATIONAL MODULES AND ITS \\ IMPACT ON DEVELOPMENT OF CHILDREN \\ ENVIRONMENTAL BEHAVIOR
}

Karm El-Din, Laila A. (1); Fahmy, A. A. ${ }^{(2)}$ and Abd Allah, M. W.

1) Institute of Postgraduate Childhood Studies, Ain Shams University

2) Faculty of Kindergarten Cairo University

\begin{abstract}
Female teacher of kindergarten considers the cornerstone in children' environmental education which targets are much difficult to be achieved without this teacher even in the availability of the most developed programs, activities, and educational media. A kindergarten female teacher has multiple responsibilities embedded in cultivating environmental behaviors in children; so, she should have environmental literacy through having environmental information characterized by environmental values and becoming an example in her proper environmental behavior to be able to orient and direct children' behavior in order to conserve the environment, protect it and resolve its problems. Therefore, the current study purpose is to develop elements of environmental literacy in female kindergarten teachers, measuring as well its impact on children' behaviors. The study counts for collecting data on these instruments:

1- Designing four educational modules for developing environmental literacy of kindergarten female teachers

2- Scale of Environmental Literacy ((information - attitudes - skills).

3- Test of children Behavior (behavioral situations-environmental behavioral interviews).
\end{abstract}

$$
\text { المجلد الثامن والثلاثون، الجزء الأول، يونيو r. V }
$$


Four educational modules are designed to develop elements of environmental literacy. The post-application of instruments is administered on a sample of (40) female teachers selected from (6) kindergartens and (200) kindergarten children. Results monitoring indicate that examining the proposed program has a remarkable impact in developing elements of environmental literacy among the kindergarten female teachers, forming as well a positive environmental behavior in children towards the environment.

The study has recommended train the kingergarten teacher to use various auto-learning approaches with their kindergarten children to develop their positive behaviors .

Keywords: Educational modules - Environmental literacy 